\title{
An Effective Power Tracking Algorithm for Partially Shaded Solar PV Array Employing Micro Converters Feeding to DC Microgrid
}

\author{
Malakondareddy Bhoreddy ${ }^{1}$, Senthil Kumar Subramaniam", \\ Ammasai Gounden Nanjappa Gounder ${ }^{1}$, Anand Isaac ${ }^{1}$ \\ 1 Department of Electrical and Electronics Engineering, National Institute of Technology, 620015 Tiruchirappalli, Tamil Nadu, India \\ * Corresponding author, e-mail: skumar@nitt.edu
}

Received: 26 February 2020, Accepted: 10 July 2020, Published online: 29 January 2021

\begin{abstract}
This paper proposes the analysis of power enhancement in partially shaded PV system supplying DC microgrid employing micro converters with a modified Perturb and Observe ( $P$ \& O) based on Maximum Power Point Tracking (MPPT) technique by sensing the load parameters alone. The proposed technique is effective in power tracking under both normal and partially shaded conditions with the reduced number of sensing devices as compared to those used in the conventional DMPPT (Distributed Maximum Power Point Tracking) techniques. In this work, two series configured micro converters are considered for supplying $120 \mathrm{~V}$ DC microgrid from partially shaded PV panels. The complete steady-state analysis is developed and predicted the performance of the proposed MPPT operation and compared with the simulation and experimental results. The PV panels are emulated in the experiments. The effectiveness of the proposed technique is demonstrated and substantiated by theoretical, simulation and experimental results under various operating conditions.
\end{abstract}

Keywords

PV system, MPPT, micro converters, DC-DC converter, DC microgrid, DMPPT, cascaded converters and cistributed generation

\section{Introduction}

The continuously increasing power demand is met by both the conventional and renewable electric power generation sources. Most of the countries have modified the electric system in order to establish the microgrids with the Distributed Generators (DGs) [1,2]. The DGs are located close to the load centers $[3,4]$ which will reduce the cost and energy loss of the transmission system. Among the DGs, solar PV and wind energy sources are the major power resources. The solar PV has remarkable technological developments due to the advantages such as less maintenance, reliability and integrability. In general, the PV power may be directly fed to the stand-alone/grid connected applications with DC-DC/DC-AC power converters. Due to the nonlinear characteristic, behavior of PV module, extracting the maximum power is a challenging task. In this regard, various MPPT techniques are proposed in the literatures [5-7].

In general, Partial Shading (PS) occurs in the solar PV module due to clouds, trees, buildings and overhead wires. Extracting the maximum power under PS conditions is considerably complex compared to that in the uniform shaded conditions. In particular, the output power of series connected PV module is significantly influenced with the PS condition [8] and creates local hotspots in unshaded panels. In such situations, the conventional MPPT algorithms are ineffective [8]. Using of bypass diode [8-11] the complete Partial Shading effect can be eliminated from the series connected PV panels. However, the PS PV modules become ineffective and multiple peaks will occur in the PV characteristic. For tracking maximum power under PS PV panels, various "global" MPPT (GMPPT) techniques have been proposed [10-14]. These strategies increase the over- all power yield but leads to complete loss of power from a PS module.

Further, to address the effect of PS and GMPPT, a micro level converter is interfaced in each PV module supplying grid connected/stand-alone loads based on the cascaded connection of micro converters.

In this scheme, the tracking of MPP of each PV module in the string is called as Distributed Maximum Power Point Tracking (DMPPT) $[15,16]$. This solution is powerful under 
PS conditions compared to the array level (GMPPT) configuration employing centralized power converter. There are two DMPPT configurations available based on the system com- posed of the PV module with the DC-DC converters. In the first configuration, the output of the PV module is connected to the input of the DC-DC converter and its output is connected in series. In this configuration the DC-DC converter tracks the full power of each PV module and it name as Full Power DC-DC (FPDC) converter [17]. In the second configuration, the output of the PV module is connected to the DC-DC converter output terminals and its input terminals are connected in parallel. In this configuration the DC-DC converter tracks maximum power based on the current compensations and is called as Compensation Power DC-DC (CPDC) converter [18]. Recently, [19, 20] have developed DMPPT technique for both FPDC and CPDC configuration and the MPPT is attained by sensing PV parameters such as $v_{p v}$ and $i_{p v}$. These methods require more number of sensors because of each PV panel requires one voltage sensor and one current sensor.

A power electronics equalizer concept is proposed in [21] for DMPPT operation, which requires ten power diodes, eight power switches and one inductor for a 4-module string. This is an inventive scheme, but the controller operation is more complex because of more power devices in this scheme.

A simple Energy Recovery scheme [22] is proposed for tracking maximum power under partial shaded condition. In this scheme a trigger circuit is required to select the shaded module and trigger the power processing circuit. This controller increases the computational process because two different control loops are required for regulating the bus voltage, and the distributed power processing converters, respectively, and also the number of sensing devices is more.

A shunt-series compensation scheme [23] is proposed for fly back converter to track maximum power under partial shaded conditions. In this scheme, the load/grid is disconnected from the input when extracting the MPP information from each module. In [24] a granular control is developed for PV arrays by sensing the output parameters. In this controller MPPT is achieved by varying the duty ratio of each converter based on output power. Due to sensing of output parameters, it requires less number of sensors but the main drawback is that it takes more time to track maximum power under partial shaded condition. A multi-winding forward-based converter developed with a current balancing DPP converter in [25] (CBC) to implement DMPPT technology at module-level and maximize the output power of the PV string during Partial Shading conditions. This method requires more number of sensing devices because of each PV panel requires one voltage sensor and one current sensor. In [26] energy management and control strategy of the DC microgrid system based on the DMPPT control technique. This paper describes the energy management by considering different source with conventional DMPPT technique and it requires more number.

The present paper develops a modified $\mathrm{P} \& \mathrm{O}$ algorithm based on approach given in [24] for the operation of partial shaded solar PV system supplying DC microgrid by sensing the output parameters. Series connected boost derived micro converters are considered for the steady-state and dynamic behavior of the solar PV system under PS conditions. The performance of the system with the proposed controller is demonstrated by simulating the system in MATLAB/Simulink and the prototype of the system has been implemented in the laboratory using a dSPACE real time controller. The efficacy of the proposed controller with a reduced number of sensing devices is verified through simulation and hardware results under various operating conditions of the solar PV system. A steady state analysis has been developed for the chosen configuration and from the steady state plots, it is observed that the proposed DMPPT controller is operating desired MPPT conditions even under varying irradiation and degradation. The paper is organized as follows: the structure, the controller operation and the steady-state analysis of series configuration of PV topology are described in Section 2; the simulation results of the series configuration under PS and degradation conditions are explained in Section 3 and the Section 4 furnishes the details of experimental investigation. The concluding remarks are summarized in Section 5.

\section{Power circuit configuration}

Fig. 1 shows the generalized schematic representation of a solar PV system with the proposed controller. The power is processed independently for each solar PV module supplying DC microgrid employing series connected micro converters. The proposed technique is capable of operating both in normal and partially shaded PV condition with the reduced number of sensing devices. For example, " $n$ " number of PV modules requires " $n$ " number of DC-DC converter, " $n-1$ " voltage sensors and one current sensor. 


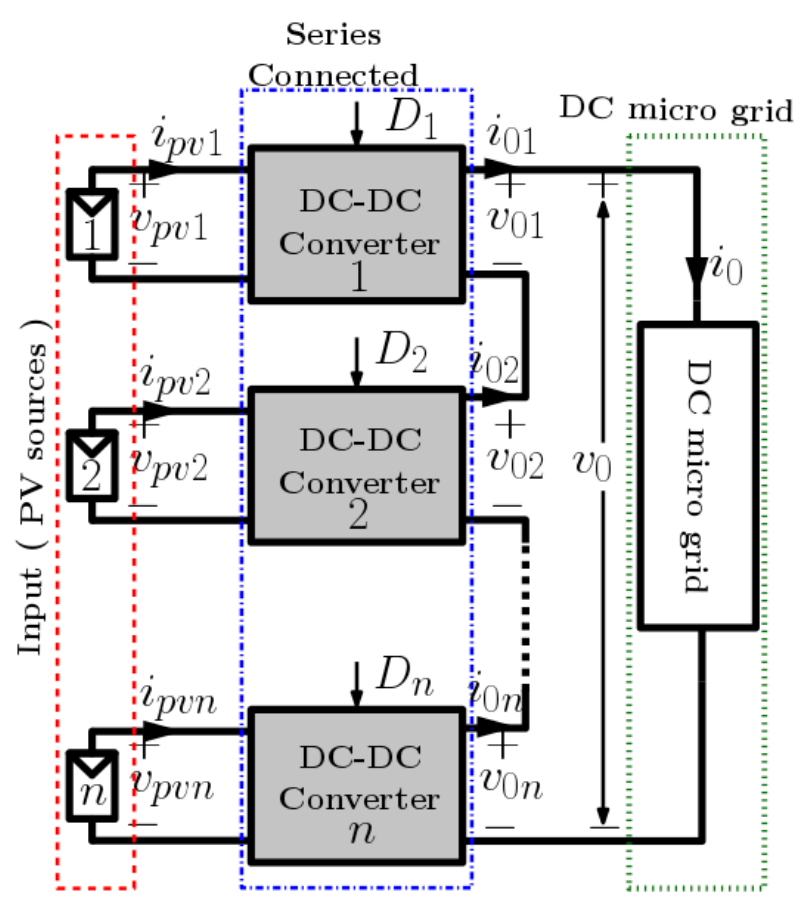

(a)

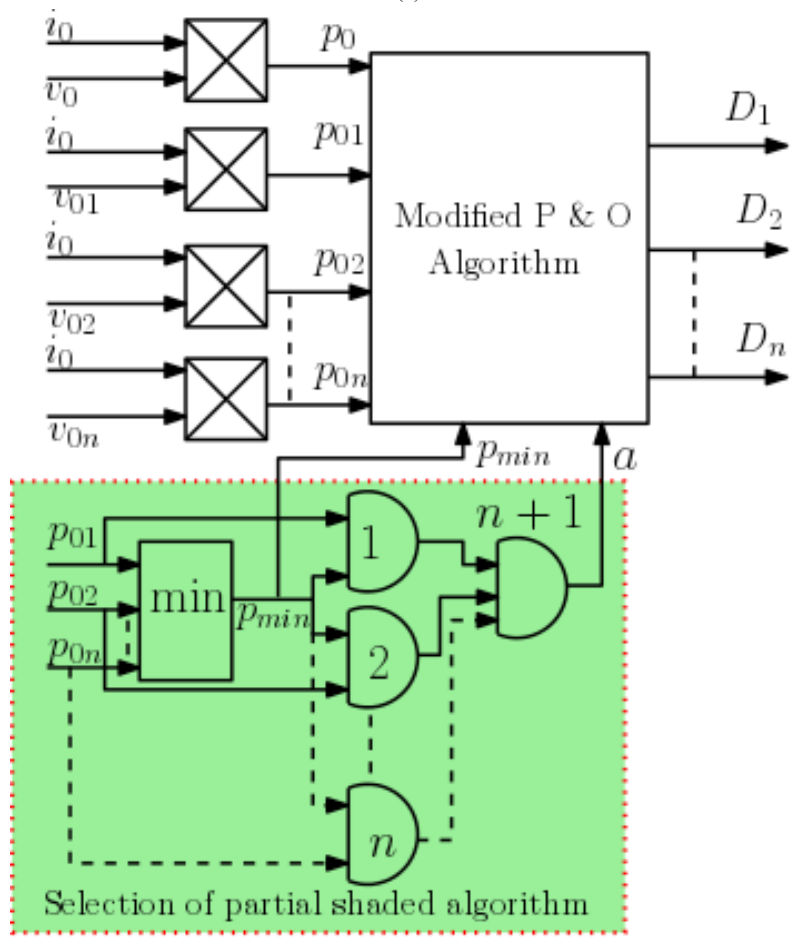

(b)

Fig. 1 Schematic representation of the DMPPT circuit (a) Series connection (b) Controller structure for series connected micro converters

\subsection{Controller strategy}

The complete generalized control structure for the MPPT operation of solar PV system employing series connected micro converter is shown in Fig. 1 (b). This control technique requires only load parameters such as $v_{01}, v_{02}, \ldots \ldots v_{0 n}$, and $i_{0}$. For considering fixed DC micro gird voltage requires $" n-1$ " voltage sensor and one current sensor, whereas the conventional methods require " $2 n$ " voltage sensors and " $2 n$ " current sensors. The sequence of proposed MPPT operation is explained using a flow chart as shown in Fig. 2. In which, the conventional $\mathrm{P} \& \mathrm{O}$ algorithm is modified to enhance the PV power generation effectively under PS conditions. To validate the performance of the proposed technique, two PV modules are considered with two series connected micro converters interface supplying DC microgrid with one voltage sensor and one current sensor. Performance prediction of the proposed control technique is observed by initially assigned with the duty ratio of each converter and the output power of each converter and the value of " $a$ " are observed. Here, " $a$ " is the output of the " $n+1 "$ AND gate, its inputs are outputs of 1 to " $n$ " AND gates. The digital logic circuit implementation for identifying the PS modules is shown in Fig. 2. If " $a$ " equal to zero, indicates that the PV modules are partially shaded and the proposed control technique works as a modified $\mathrm{P} \& \mathrm{O}$ algorithm. This will reduce the duty ratio of the corresponding shaded PV panel converter and increases the duty ratio of the non-shaded PV module converter based on the conditions given in the flow chart as shown in Fig. 2. This sequence contentious till all the converters reach their maximum powers. If the value of " $a$ " equals 1 , which means no shaded on the panels at this condition the proposed technique works similar to conventional P \& O algorithm [5]. The complete steps of the modified $\mathrm{P} \& \mathrm{O}$ algorithm are given in Fig. 2.

In the proposed modified $\mathrm{P} \& \mathrm{O}$ algorithm, the frequency of perturbations, or the time interval ta between two consecutive perturbations, and their amplitude must be carefully chosen to optimize the dynamic performances and the steady-state efficiency of the MPPT algorithm. The value of the parameter ta must be selected on the basis of the DC-DC converters dynamic behavior [5]. In this paper, the settling time of the response of the DC-DC converters output current to a step variation of the duty cycle is evaluated. Consequently, the optimal $t_{a}$ value does not change when a classical Single Variable (SV) P \& O algorithm or the proposed algorithm is used. In this, $t_{a}=1 \mathrm{~ms}$ which is equal to $1000 \mathrm{~Hz}$ of execution frequency. Whereas in case of $\Delta D$, the above conclusion cannot come because the oscillations of the outputs around the steady-state values depend on $\Delta D$. A small step size will take more time to reach MPP or it may oscillate around the reference voltage in the case of high step size. Due to this, an optimal $\Delta D$ must be chosen. 


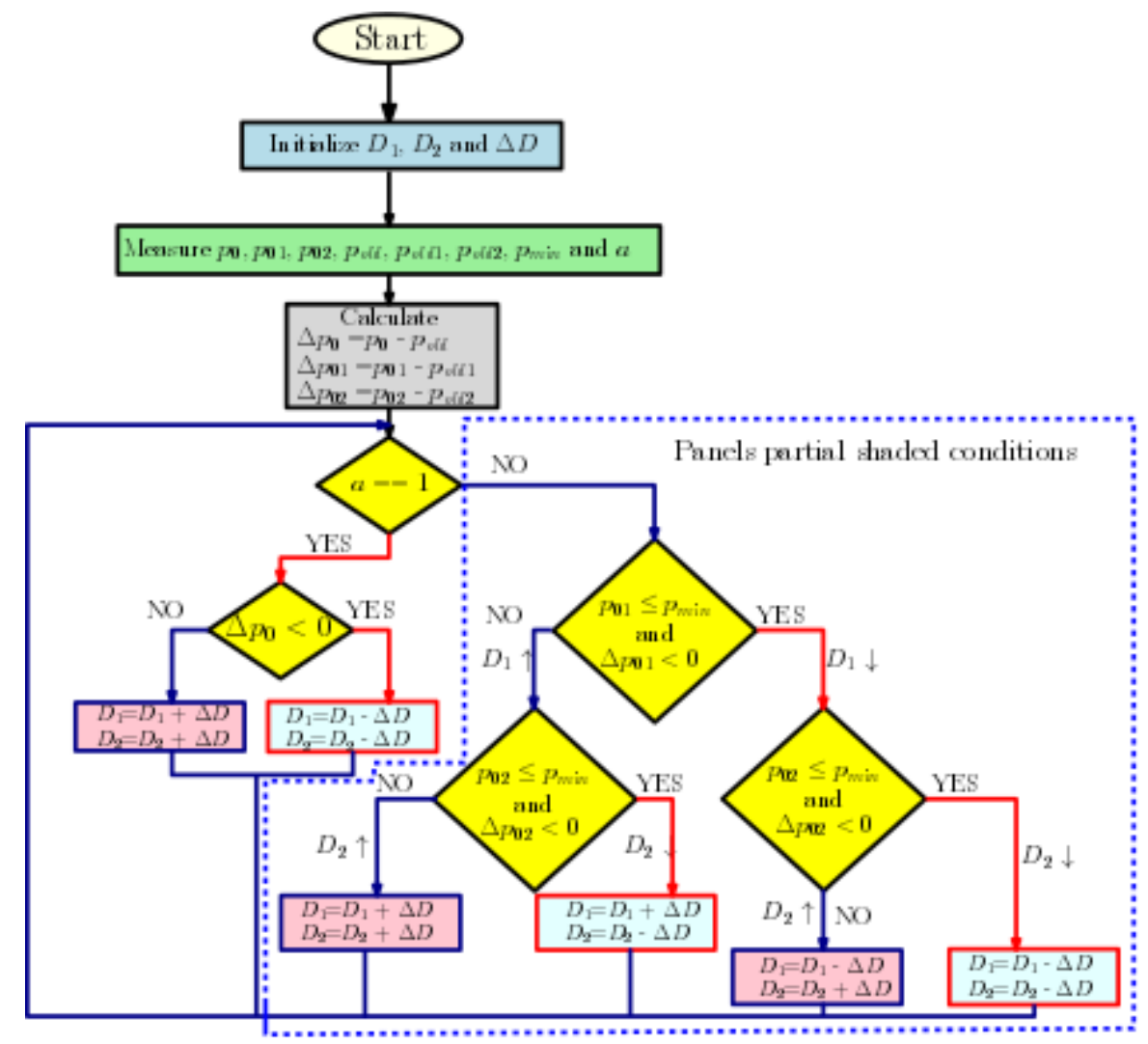

Fig. 2 Flow chart for modified $\mathrm{P} \& \mathrm{O}$ algorithm, execution frequency $=1000 \mathrm{~Hz}, \Delta D=0.00241$

The optimum value of $\Delta D$ is calculated using the following expression

$$
\Delta D=\frac{1}{G_{0}} \sqrt{\frac{N V_{\mathrm{MPP}} K \Delta S t_{a}}{H V_{\mathrm{MPP}}+\frac{1}{R_{\mathrm{MPP}}}},}
$$

where $G_{0}$ is reference irradiation, $\left(1000 \mathrm{~W} / \mathrm{m}^{2}\right), N$ is number of DC-DC converters, $V_{\text {MPP }}$ is maximum PV voltage at $200 \mathrm{~W} / \mathrm{m}^{2}(27.65 \mathrm{~V}), K$ is a coefficient proportional to derivative of the PV current with respect to the irradiance, $\left(6.895 \times 103, \mathrm{Am}^{2} / \mathrm{W}\right), R_{\mathrm{MPP}}$ is the differential resistance of the PV module evaluated in its MPP, $H$ is a coefficient proportional to the second derivative of $\mathrm{PV}$ current with respect to the $\mathrm{PV}$ voltage $\left(5.9 \times 10^{4}, \mathrm{~A} / \mathrm{v}^{2}\right), D S$ is constant rate of change equal to $50 \mathrm{~W} / \mathrm{m}^{2} \mathrm{~s}$. The optimum value of $D D$ from the above values is 0.00241 .

\subsection{Steady state analysis}

The steady-state analysis of the system considered is organized into two parts. Firstly, the performance of the PV panels are analyzed under various operating conditions and secondly, the mathematical analysis of the boost derived DC-DC converter is developed.

\subsubsection{Performance of PV panels}

The performance of the PV panels is analyzed with the mathematical modelling given in [27, 28]. A PV cell is modeled as a current source shunted with a diode and represented by an equivalent circuit [27] shown in Fig. 3. The characteristics of the panel are obtained by connecting a number of such cells in series. The equation relating the output current and the voltage of a PV module can be written as

$$
\begin{aligned}
& I_{\mathrm{PV}}=I_{p h}-I_{s a t}\left\{\exp \left[\frac{V_{\mathrm{PV}}+I_{\mathrm{PV}} R_{s}}{n\left(\frac{K T_{c}}{q}\right)}\right]-1\right\}-\frac{V_{\mathrm{PV}}+I_{\mathrm{PV}} R_{s}}{R_{s h}} \\
& T_{c}-T_{a}=\frac{\mathrm{NOCT}-20}{800} \times G_{0} .
\end{aligned}
$$

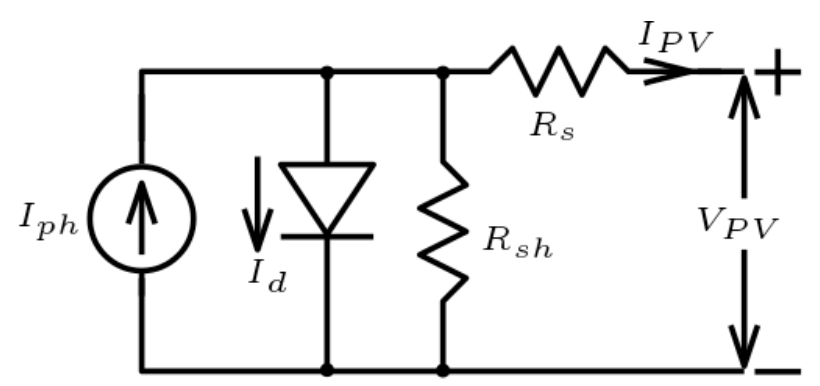

Fig. 3 Equivalent circuit of a PV cell 
The following steps give the complete detail of PV panel performance.

Step 1: Calculate the junction temperature $T_{c}$ using the Eq. (2).

Step 2: Calculate the saturation current $I_{\text {sat }}$ and the photocurrent $I_{P h}$ using the Eq. (4) and Eq. (5)

$$
\begin{aligned}
& I_{s a t}=\frac{I_{c c} \times\left(1+\frac{R_{s}}{R_{p}}\right)-\frac{V_{o c}}{R_{p}}}{\exp \left(\frac{q \times V_{o c}}{n K T_{c}}\right)-\exp \left(\frac{q \times I_{c c} \times R_{s}}{n K T_{c}}\right)} \\
& I_{\mathrm{PV}}=I_{s a t}\left\{\exp \left[\frac{V_{o c}}{n\left(K T_{c} / q\right)}\right]-1\right\}-\frac{V_{o c}}{R_{s h}} .
\end{aligned}
$$

Step 3: Solve the Eq. (2) and plot the current-voltage characteristics and the power-voltage characteristics.

Step 4: By using program, it can directly solve the Eq. (2), but in the form of two equations, Eq. (6) and Eq. (7)

$$
\begin{aligned}
& X\left(V_{\mathrm{PV}}, I_{\mathrm{PV}}\right)=I_{s a t}\left\{\exp \left[\frac{V_{\mathrm{PV}}+R_{s} \times I_{\mathrm{PV}}}{n\left(K T_{c} / q\right)}\right]-1\right\} \\
& Y\left(V_{\mathrm{PV}}, I_{\mathrm{PV}}\right)=I_{p h}-\frac{V_{\mathrm{PV}}}{R_{s h}}-\left(\frac{R_{s}}{R_{p}}+1\right) \times I_{\mathrm{PV}} .
\end{aligned}
$$

Step 5: Find the maximum power, then the maximum voltage and the maximum current without calculation.

The meanings of the symbols in Eqs. (2)-(7) are as follows $I_{s c}$ : short-circuit current (A), $V_{o c}$ : open-circuit voltage $(\mathrm{V}), R_{s}$ : series resistance $(\Omega), R_{s h}$ : parallel resistor (shunt) to the diode $(\Omega), k: 1.38 \times 10^{-23} \mathrm{~J} / \mathrm{K}$, Boltzmann constant, $q: 1.602 \times 10^{-19}$ electron charge (C), $T_{c}:$ junction temperature $(\mathrm{K}), n$ : ideality factor of the solar cell, between 1 and 5 in practice, NOCT: Nominal Operating Cell Temperature, $T_{a}$ : ambient temperature and $G_{0}$ : irradiance $\left(\mathrm{W} / \mathrm{m}^{2}\right)$.

Fig. 4 (a) and (b) shows the Maximum Power Points (operating points) under different irradiation and series resistance of the PV panels respectively. The MPP operation is obtained by the steps given in the flow chart (Fig. 5).

\subsubsection{DC microgrid connected boost converter}

After calculating the PV operating points, it is of interest to analyze the performance of the boost converter. Therefore, in this section, a technique is developed to find the duty ratio of the micro converter to operate the PV panels at MPP.

\subsubsection{Cascaded boost converter}

The current passing through all boost converters is same and the microgrid voltage is equal to the sum of the individual boost converter voltages.

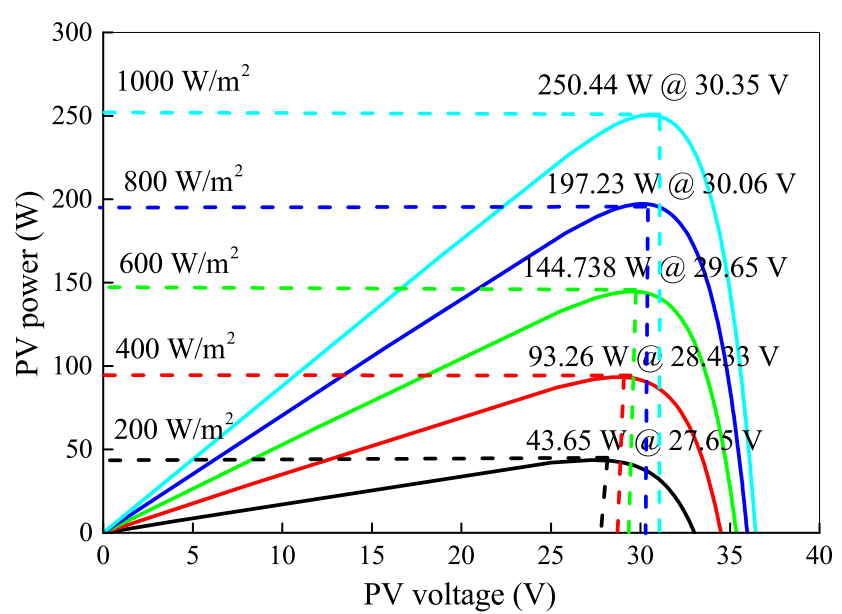

(a)

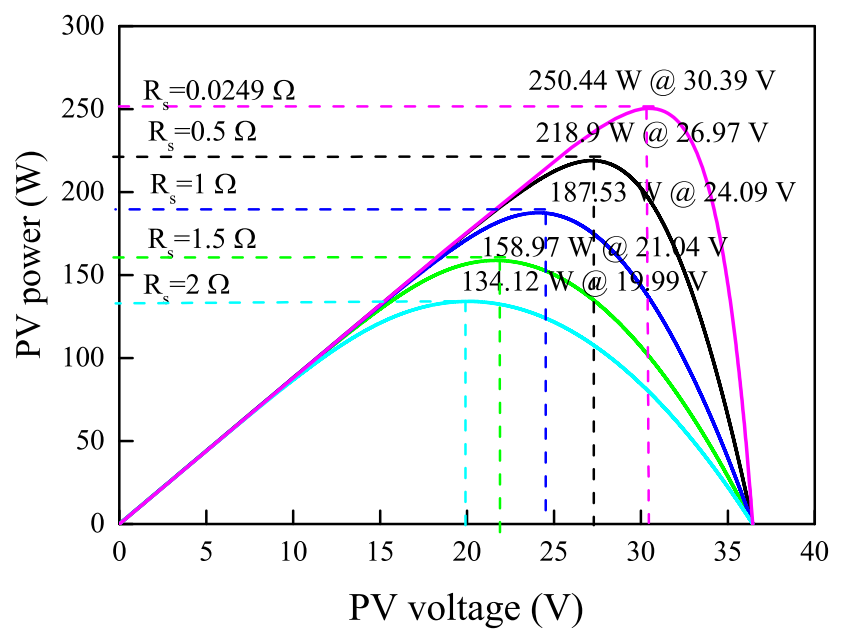

(b)

Fig. 4 PV characteristics under (a) different irradiation (b) different series resistance of the panel

$V_{0}=\sum_{i=1}^{n} v_{o i}$

The microgrid power is the sum of the powers of the individual boost converters that is equal to the sum of the maximum input $\mathrm{PV}$ power when losses are zero.

$P_{0}=V_{0} \times i_{0}=\sum_{i=1}^{n} v_{0 i} \times i_{0 i}=\sum_{i=1}^{n} v_{\mathrm{PV} i} \times i_{\mathrm{PV} i}$

Equation (9) represents the power balance equation assuming that the power losses are zero.

The converter voltage and current are represented as

$v_{o i}=V_{0} \times \frac{v_{\mathrm{PVi}} \times i_{\mathrm{PVi}}}{\sum_{i=1}^{n} v_{\mathrm{PVi}} \times i_{\mathrm{PVi}}}$

$i_{o i}=\frac{\sum_{i=1}^{n} v_{\mathrm{PV} i} \times i_{\mathrm{PV} i}}{V_{0}}$. 


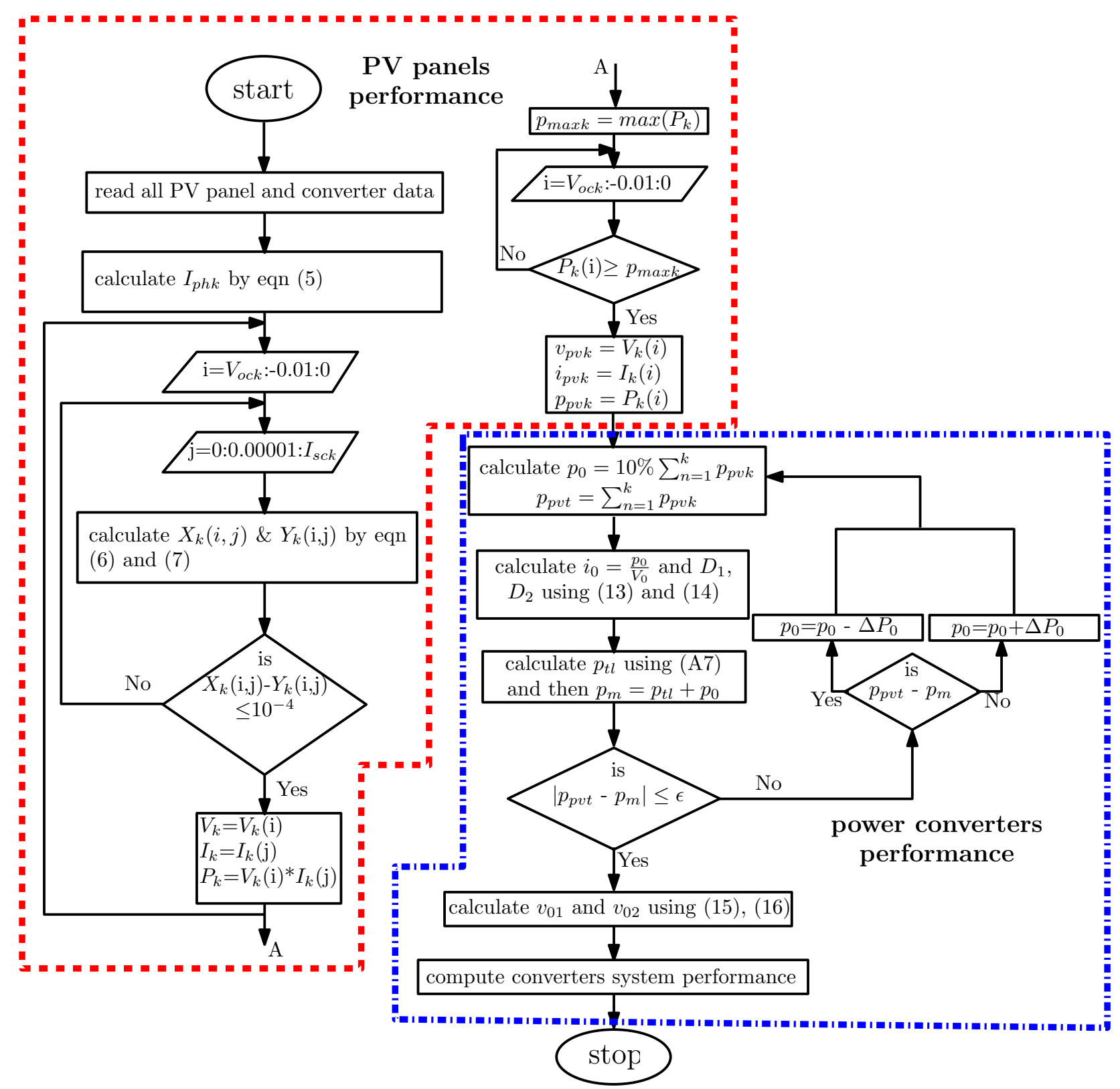

Fig. 5 Flowchart for predetermining the steady-state performance of the PV fed boost converter connected to DC microgrid. $k=$ number of panels, $\varepsilon=0.01$ and $\Delta P_{0}=0.01$

Considering two boost converters connected in series, the $\mathrm{DC}$ behavior of this topology is described by where,

$i_{01}=i_{02}=i_{0}$

$i_{0}=i_{\mathrm{PV} 1} \times\left(1-D_{1}\right)$

$i_{0}=i_{\mathrm{PV} 2} \times\left(1-D_{2}\right)$

$v_{01}=\frac{v_{\mathrm{PV} 1}}{1-D_{1}}$

$v_{02}=\frac{v_{\mathrm{PV} 2}}{1-D_{2}}$.
However, for carrying out this analysis, the total converter loss is required and the procedure to calculate the converter loss is depicted in the Appendix A. The total output power is the sum of the input power and the converter losses.

$P_{0}=P_{\mathrm{PV} t}+P_{t l}$

From Eqs. (8)-(17), it can be observed that the values of $i_{0}, P_{0}$ and $P_{t l}$ are essential for finding the duty ratios. Initially, the values are not known for the pre-determination process. Hence, a simple technique is designed to find the initial values of $i_{0}, P_{0}$ and $P_{t l}$ on the basis of power balance and known parameters (given in the Appendix A). The complete steps for the analysis are given in Fig. 2 for finding the duty ratio. 


\section{Results and discussion}

The complete solar PV system supplying a DC microgrid shown in Fig. 1, has been developed using MATLAB/ Simulink toolbox.

The proposed DMPPT operation has been validated for series connected boost derived micro converters under different case studies with a reduced number of sensors. The system parameters considered for these case studies are given in Table 1 .

\subsection{Steady state performance}

The steady state performance of the system with the proposed controller is shown in Fig. 6. Fig. 6 (a) and (b) shows the plots of the operating points $\left(D_{1}, D_{2}, V_{01}, V_{02}\right.$ and $\left.P_{0}\right)$ with respect to different irradiation and series resistance of PV panels respectively. From Fig. 6 (a) it is observed that, the series configuration with an irradiation less than $400 \mathrm{~W} / \mathrm{m}^{2}$ results in a negative duty ratio. Hence, this configuration can only be operated up to $400 \mathrm{~W} / \mathrm{m}^{2}$. Further, the closeness of the simulated, experimental and calculated values confirms that the proposed controller is working effectively for both PS and degradation conditions as shown in Fig. 6 (a) and (b).

\subsection{Comparison of DMPPT configuration with and without bypass diode configuration}

Fig. 7 shows the different configuration under PS condition. In Fig. 8, PV panel 1 has $1000 \mathrm{~W} / \mathrm{m}^{2}$ and PV panel 2 irradiation is varying from $1000 \mathrm{~W} / \mathrm{m}^{2}$ to $200 \mathrm{~W} / \mathrm{m}^{2}$, that is represented as $x$ in the Fig. 7 .

\subsection{Simulation results}

The simulation is carried out to evaluate the proposed controller performance under various operating conditions of solar PV system such as change in irradiation and degradation.

\subsubsection{Series configuration}

The effect of PS has been studied through simulation with step change in irradiation. In this study, Fig. 1 (a) is considered to validate the controller. Fig. 9 (a) and (b) shows the simulation results of the solar PV system with DMPPT operation. By setting DC microgrid voltage at $120 \mathrm{~V}$ and the solar irradiation at $1000 \mathrm{~W} / \mathrm{m}^{2}$ from time $t=0.04 \mathrm{~s}$ to $0.1 \mathrm{~s}$ for both the PV panels, the corresponding PV volt$\operatorname{ages}\left(v_{\mathrm{PV} 1}=v_{\mathrm{PV} 2}=30.5 \mathrm{~V}\right)$, currents $\left(i_{\mathrm{PV} 1}=i_{\mathrm{PV} 2}=8.21 \mathrm{~A}\right)$ and powers $\left(p_{\mathrm{PV} 1}=p_{\mathrm{PV} 2}=250.4 \mathrm{~W}\right)$ are observed. During this duration, it is noticed that, both the converters are sharing the microgrid voltage $\left(v_{01}=v_{02}=60 \mathrm{~V}\right)$. The corresponding
Table 1 Parameters

\begin{tabular}{lc}
\hline Parameters & Values \\
\hline Maximum PV voltage & $30.5 \mathrm{~V}$ \\
Maximum PV current & $8.21 \mathrm{~A}$ \\
Inductor & $1.5 \mathrm{mH}$ \\
Capacitors & $1000 \mu \mathrm{F}$ \\
Switching frequency & $20 \mathrm{kHz}$ \\
Micro grid voltage & $120 \mathrm{~V}$ (series) \\
\hline
\end{tabular}

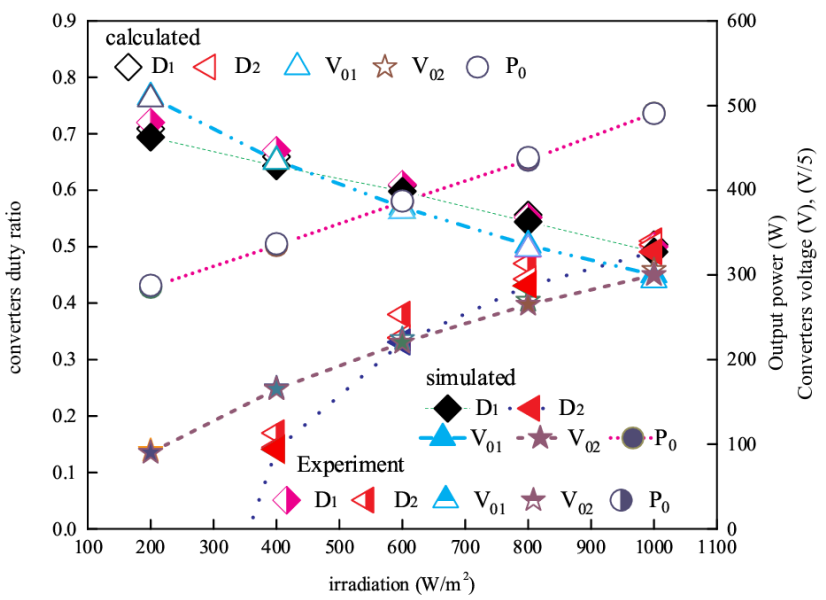

(a)

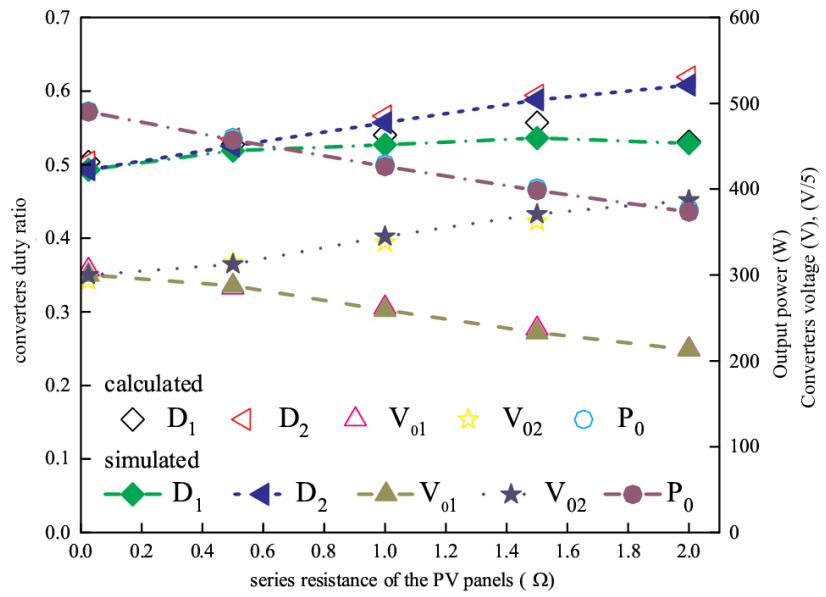

(b)

Fig. 6 Performance of the boost converter for duty ratio and converter voltages under various (a) irradiation and

(b) series resistance of the PV panels
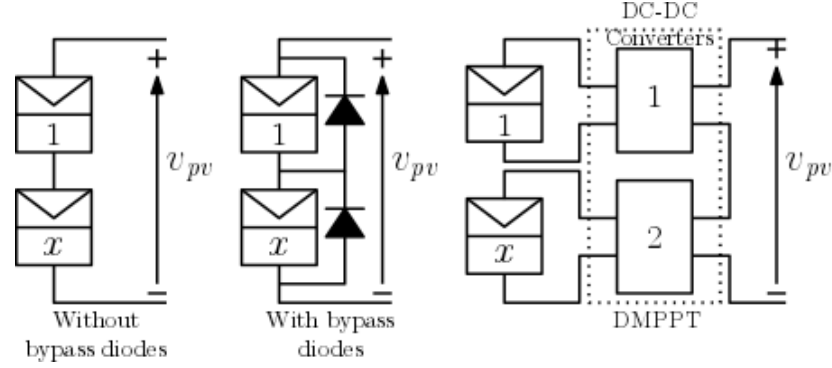

Fig. 7 Different types of configuration $\left(x \in 800,600,400\right.$ and $\left.200 \mathrm{~W} / \mathrm{m}^{2}\right)$ 


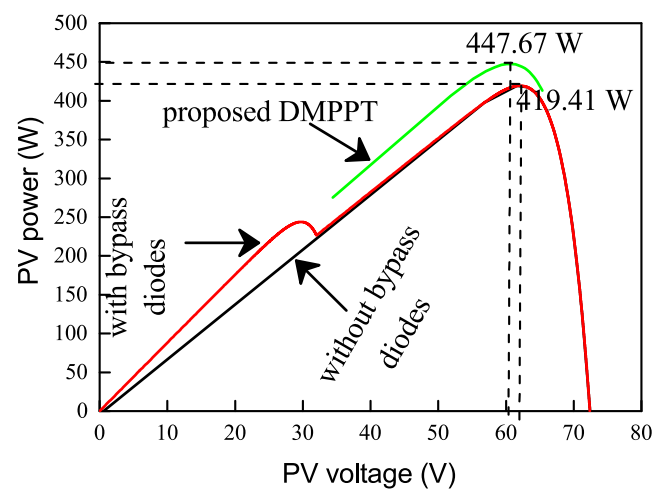

(a)

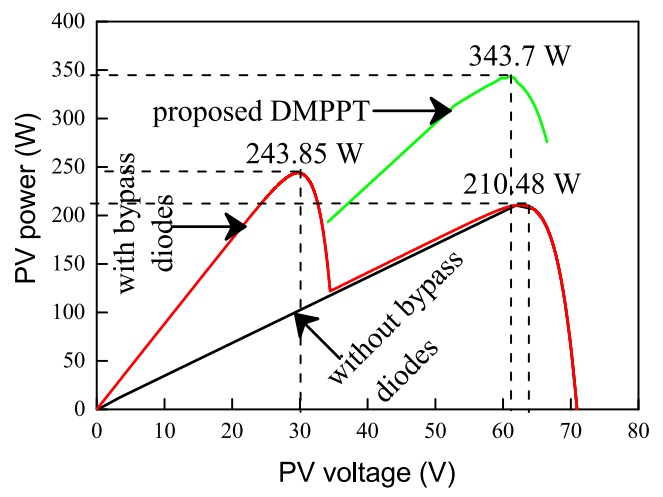

(c)

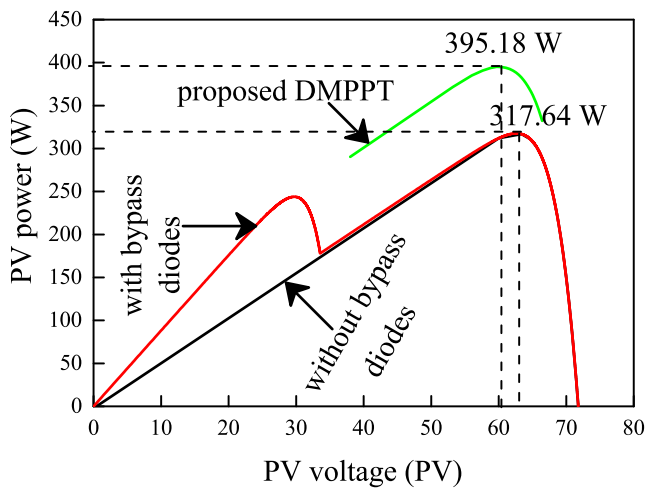

(b)

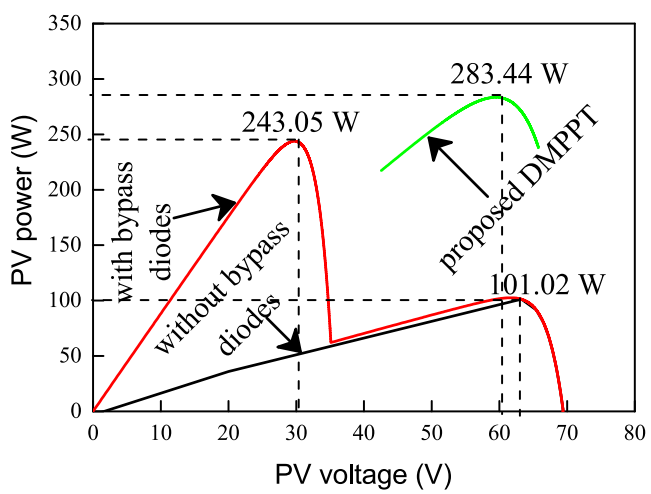

(d)

Fig. 8 Power-voltage plots of the PV panels with, without bypass diodes and the proposed DMPPT configuration for panel 1 (1000 W/m $\left.{ }^{2}\right)$, (a) panel $2\left(800 \mathrm{~W} / \mathrm{m}^{2}\right)\left(\right.$ b) panel $2\left(600 \mathrm{~W} / \mathrm{m}^{2}\right)(\mathrm{c})$ panel $2\left(400 \mathrm{~W} / \mathrm{m}^{2}\right)(\mathrm{d})$ panel $2\left(200 \mathrm{~W} / \mathrm{m}^{2}\right)$

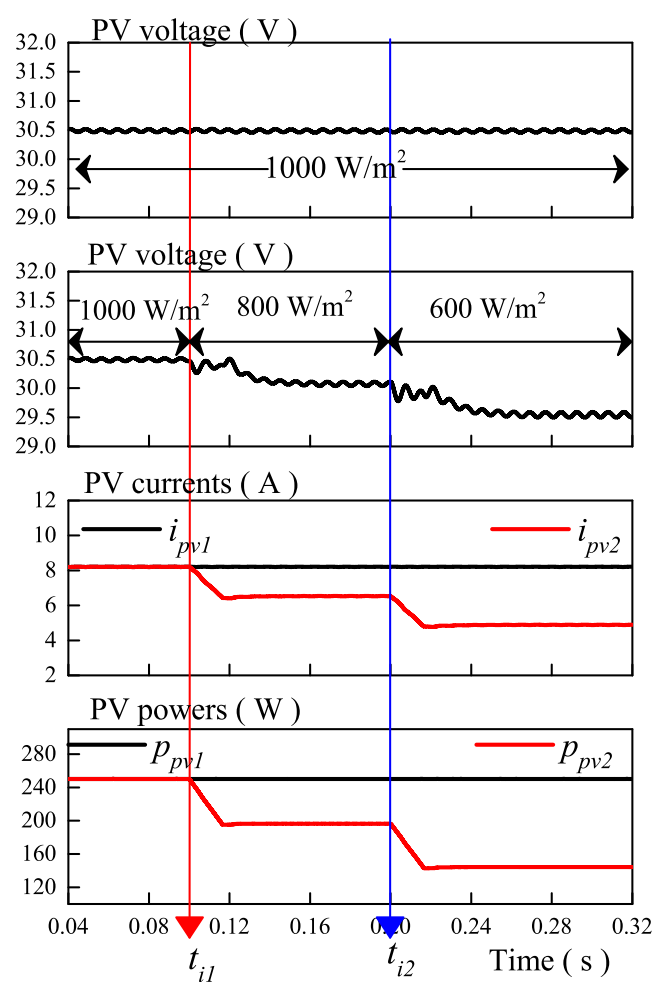

(a)
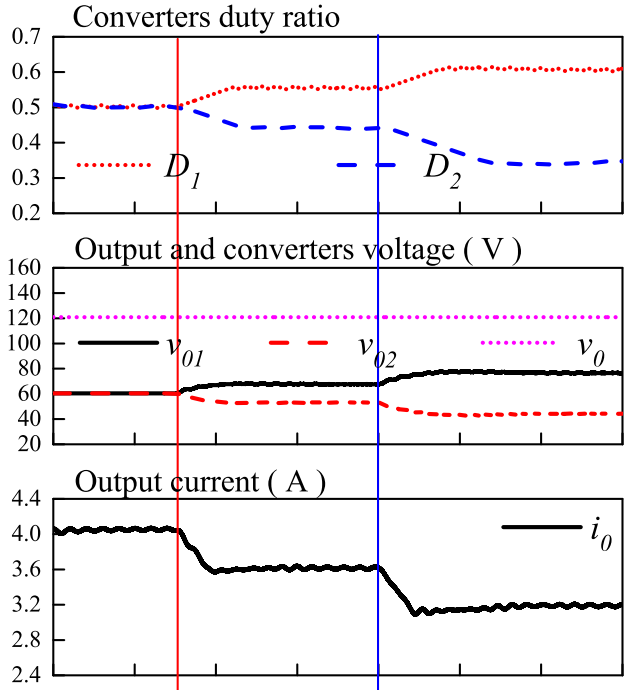

Output and converters power ( W )

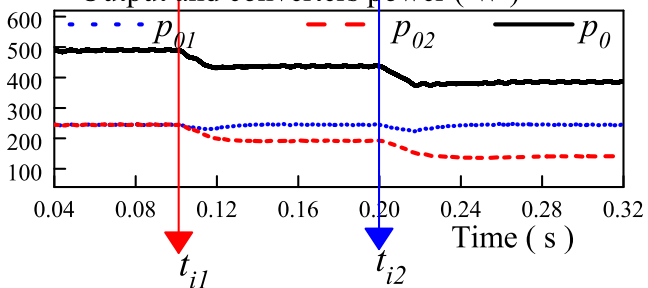

(b)

Fig. 9 Simulation results: (a) PV voltages, currents and powers (b) converter duty ratio, voltages, currents and powers for series connected boost converters with step change in irradiation in panel 2 
current at each converter $i_{01}=i_{02}=4.09 \mathrm{~A}$, the power outputs $p_{01}=p_{02}=245.4 \mathrm{~W}$ and the total power fed to the microgrid terminals is $490.8 \mathrm{~W}$.

Fig. 9 (a) and (b) also shows the performance for the dynamic variation in the irradiation of the solar PV panels. With the same level of microgrid voltage $(120 \mathrm{~V})$ and standard irradiation of $\left(1000 \mathrm{~W} / \mathrm{m}^{2}\right)$ for panel 1 at time $t=0.1 \mathrm{~s}$ a step change in irradiation for panel 2 is applied from $\left(1000 \mathrm{~W} / \mathrm{m}^{2}\right.$ to $\left.800 \mathrm{~W} / \mathrm{m}^{2}\right)$. In this duration, the PV panel voltages $\left(v_{\mathrm{PV} 1}=30.5 \mathrm{~V}\right.$ and $\left.v_{\mathrm{PV} 2}=30.1 \mathrm{~V}\right)$, currents $\left(i_{\mathrm{PV} 1}=8.21 \mathrm{~A}\right.$ and $\left.i_{\mathrm{PV} 2}=6.53 \mathrm{~A}\right)$, powers $\left(p_{\mathrm{PV} 1}=250.4 \mathrm{~W}\right.$ and $\left.p_{\mathrm{PV} 2}=196.5 \mathrm{~W}\right)$ together with power supplied to the DC microgrid (446.9 W) are observed. Further, the DMPPT controller adjusts the duty ratio to the desired value $\left(D_{1}=0.491\right.$ to 0.544 and $D_{2}=0.491$ to 0.431$)$ under varying irradiation to maintain the constant value of the output current (3.63 A) of the series converters. Further, it is observed that the converter 1 voltage is raised to $67 \mathrm{~V}$ and converter 2 is dropped to $53 \mathrm{~V}$. Similarly, at time $t=0.2 \mathrm{~s}$ the step change in irradiation for panel 2 is reduced from $800 \mathrm{~W} / \mathrm{m}^{2}$ to $600 \mathrm{~W} / \mathrm{m}^{2}$. In this duration, the PV panel voltages $\left(v_{\mathrm{PV} 1}=30.5 \mathrm{~V}\right.$ and $\left.v_{\mathrm{PV} 2}=29.4 \mathrm{~V}\right)$, currents $\left(i_{\mathrm{PV} 1}=8.21 \mathrm{~A}\right.$ and $\left.i_{\mathrm{PV} 2}=4.92 \mathrm{~A}\right)$, powers $\left(p_{\mathrm{PV} 1}=250.4 \mathrm{~W}\right.$ and $p_{\mathrm{PV} 2}=144.6 \mathrm{~W}$ ) and power fed to the DC microgrid are observed. The duty ratio of each power converter ( $D_{1}=0.544$ to 0.598 and $D_{2}=0.431$ to 0.331 ) is adjusted by the controller to maintain the constant value of the converters output current (3.22 A) to ensure DMPPT operation. The results show that the converter 1 voltage raised to $76 \mathrm{~V}$ and converter 2 voltage dropped to $44 \mathrm{~V}$.

\subsubsection{Degradation of the panels}

The effect of the degradation in the PV module is a gradual drop in output power over time [29], [30].

This is because of:

1. increases in $R_{s}$ and

2. reduction in $R_{s h}$.

By considering the degradation in the module, a dynamic simulation study has been performed with the series connected configuration to validate DMPPT operation.

In this case, the step change in $R_{s}$ in the PV modelling is considered and the corresponding dynamic simulation results are given in Fig. 10. From this figure, it is noticed that for any change in $R_{s}$, the duty ratio $\left(D_{1}=0.493,0.527\right.$ and 0.536 and $D_{2}=0.493,0.557$ and $0.588)$ is adjusted by the controller to maintain the output currents $\left(i_{01}=i_{02}=4.06 \mathrm{~A}, 3.53 \mathrm{~A}\right.$ and $\left.3.3 \mathrm{~A}\right)$. Also, the

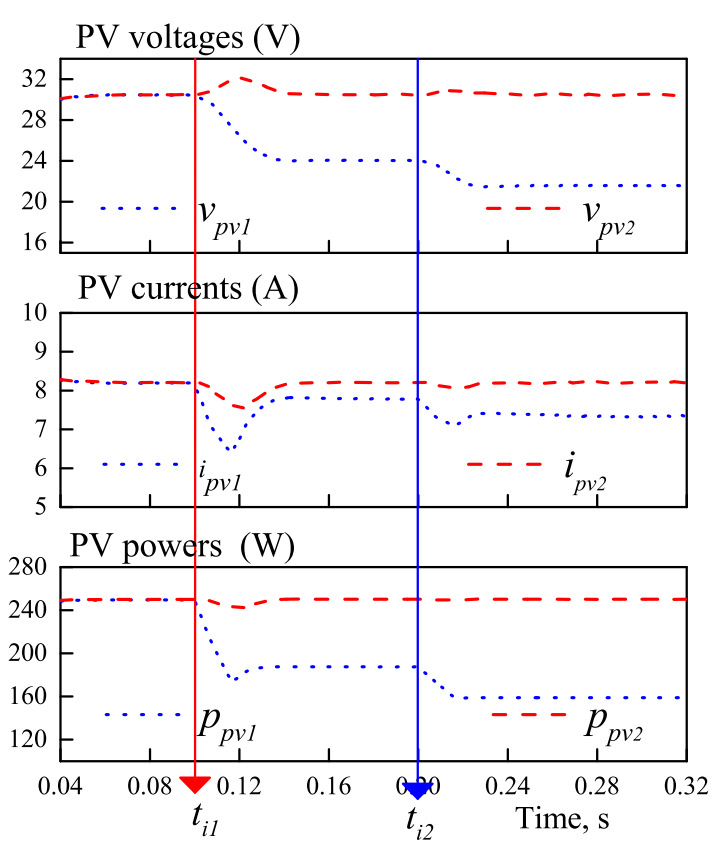

(a)

converters duty ratio

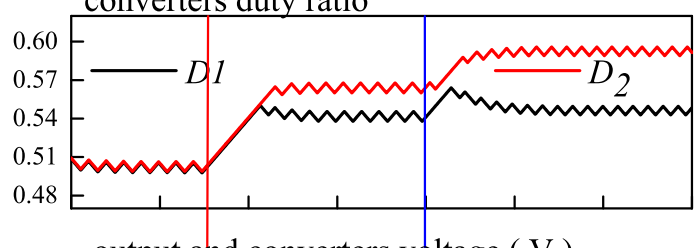

40 output and converters vфltage ( V)

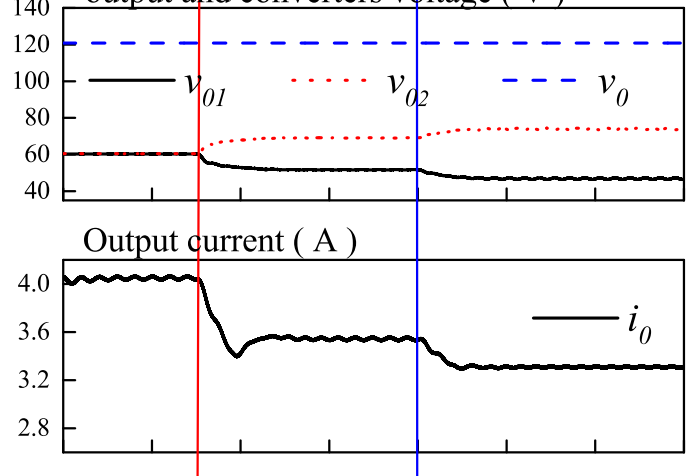

output and converters power ( W )

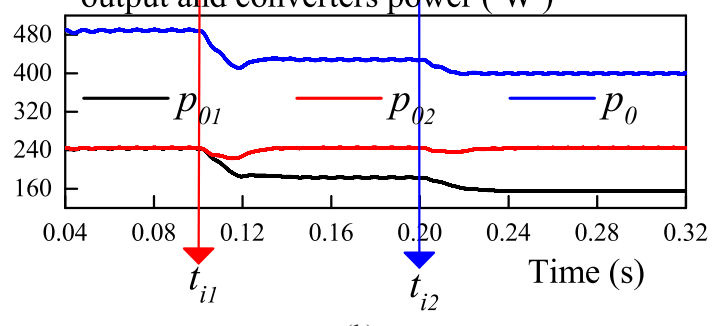

(b)

Fig. 10 Simulation results for series connected boost converters with degradation on panel 1 (a) PV voltages, currents and powers (b) converter duty ratio, voltages, currents

corresponding variation in the converter output voltage sums up to the DC microgrid voltage to validate the correctness of the controller operation. 


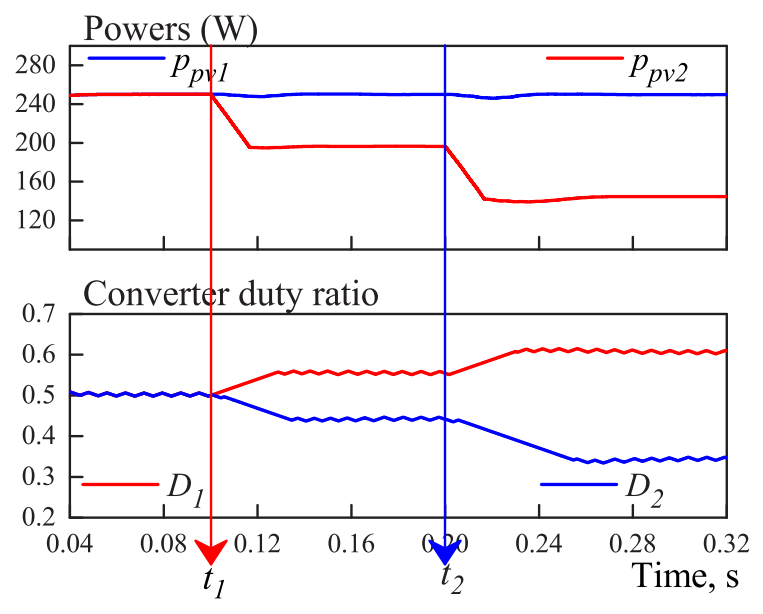

(a)

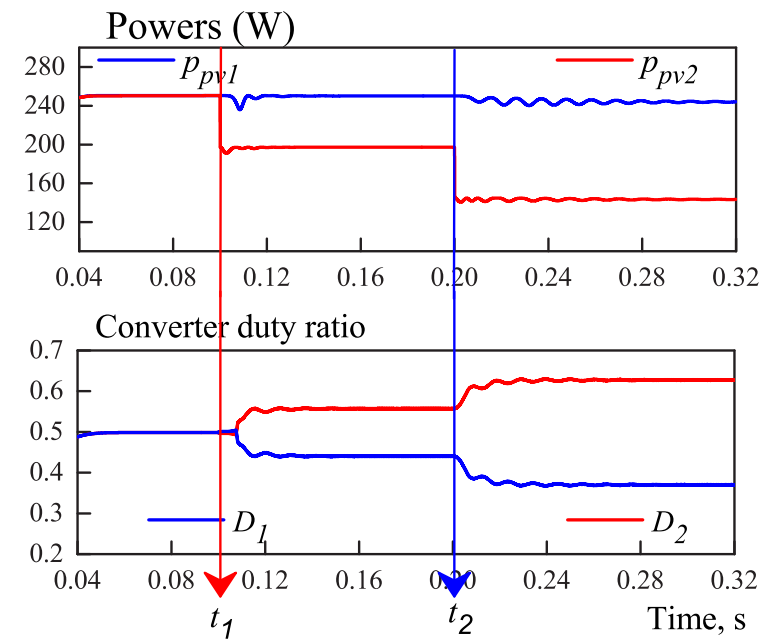

(b)

Fig. 11 Simulation results of PV powers and duty ratio for (a) proposed controller (b) conventional controller

\subsection{Comparison of the proposed controller with convention controller}

To demonstrate the superiority of the proposed controller it is compared with the conventional controller and the comparison results are shown in Fig. 11 (a) and (b). It can be observed from these figures that the proposed controller is effectively tracking the maximum power under the shaded condition similar to the conventional controller. But the conventional controller requires additional sensors compared to the proposed controller. The complete result and sensors requirement are given in Table 2. From this table it is observed that the proposed controller requires only one voltage and one current sensor whereas the conventional controller requires two voltage and two current sensors in case of two series connected micro converters.

Table 2 Performance evaluation of proposed with conventional controller

\begin{tabular}{|c|c|c|c|c|c|}
\hline \multirow{2}{*}{ Controller } & \multirow{2}{*}{$\begin{array}{c}\text { No. of } \\
\text { converters }\end{array}$} & \multicolumn{2}{|c|}{ sensors } & \multirow{2}{*}{ MPPT } & \multirow{2}{*}{$\begin{array}{l}\text { Settling } \\
\text { (ms) }\end{array}$} \\
\hline & & voltage & current & & \\
\hline Proposed & 2 & 1 & 1 & yes & 30 \\
\hline Conventional & 2 & 2 & 2 & yes & 30 \\
\hline
\end{tabular}

\section{Experimental results}

The series connected two DC-DC converters are fabricated using IGBT (IRGTI090U06) switches, diodes (IXYS DSEI30-06A), $1.5 \mathrm{mH}$ inductor and $1000 \mathrm{mF}$ capacitors. The proposed modified P \& O algorithm has been implemented in the dSpace DS1103 prototyping platform by programming in the MATLAB/Simulink environment. Gating pulses were generated by using the dSpace platform. The $v_{\mathrm{PV}}$ and $p_{\mathrm{PV}}$ were averaged over a $10 \mathrm{~ms}$ interval and the MPPT control is run every $1 \mathrm{~ms}$. A solar PV module with a $P_{\text {MPP }}=250 \mathrm{~W}, V_{\mathrm{MPP}}=30.5 \mathrm{~V}$ and $I_{\mathrm{MPP}}=8.21 \mathrm{~A}$ is emulated in the $2 \mathrm{~kW}$ Chroma solar simulator $62020 \mathrm{H}-150 \mathrm{~S}$ [Chroma (2014)]. Hall effect voltage transducers and current sensors were used to sense output voltage and output currents of the converters. Also, a Digital Storage Oscilloscope (DSO) is used to captured the experimental results. Two gate drive circuits with galvanic isolation have been fabricated using the FOD3182SDV [On Semiconductor (2011)] optocoupler and the TMH1215D [Traco Power (2011)] isolated DC-DC converter chip. The schematic of the fabricated gate drive circuit drawn in Kicad-Eeschema. The complete experimental set up shown in Fig. 12.

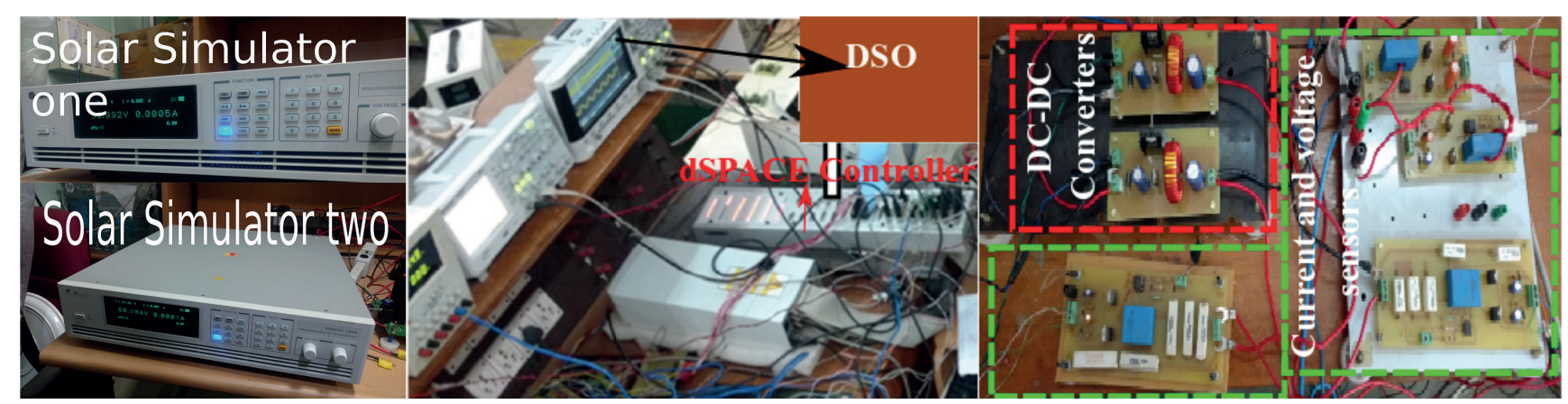

Fig. 12 Experimental setup for proposed controller 
Fig. 13 shows the experimental results of the PV system with DMPPT operation and for a DC micro grid voltage of $120 \mathrm{~V}$. From Fig. 13 , it is observed that up to $t=t_{p 1}[\mathrm{~s}]$ both panels are unshaded $\left(1000 \mathrm{~W} / \mathrm{m}^{2}\right)$ and the results of panel voltage, current, power, duty ratio, converter voltage, current and power are shown. At $t=t_{p 1}[\mathrm{~s}]$, the panel 2 is partially shaded $\left(800 \mathrm{~W} / \mathrm{m}^{2}\right)$ and panel 1 remains unshaded $\left(1000 \mathrm{~W} / \mathrm{m}^{2}\right)$. It is observed that converter 1 voltage is increased, and converter 2 voltage is decreased with respect to duty ratio to maintain the same current at both the converters.

Similarly at $t=t_{p 2}[\mathrm{~s}]$, the panel 2 is further partially shaded $\left(600 \mathrm{~W} / \mathrm{m}^{2}\right)$ and the converter 1 voltage is increased and converter 2 voltage is decreased with respect to duty ratio for maintaining the same current at the both the converters. From the results shown in Fig. 13, it can be observed that the proposed controller is effectively working under PS condition.

\section{Conclusion}

The series connected boost derived micro converter configuration has been developed for MPPT operation of solar PV system under PS conditions supplying DC microgrid. This has been performed with modified P \& O algorithm with a reduced number of sensors compared to that of the conventional DMPPT operation. The complete system has been developed using MATLAB/Simlink tool box and dSPACE(rti 1103) real time controller. The effectiveness of the DMPPT operation has been validated through different conditions such as step change in irradiation and degradation of the PV panels. Steady state and dynamic results obtained under various operating conditions show that the proposed control algorithm with the reduced number of sensors is effective in tracking the maximum power of PV panels in series configurations.

\section{Nomenclature}

MPP: Maximum Power Point

MPPT: Maximum Power Point Tracking

DMPPT:Distributed Maximum Power Point Tracking

GMPPT:Global Maximum Power Point Tracking

FPDC: Full Power DC-DC Converter

CPDC: Compensation Power DC-DC converter

DSO: Digital Storage Oscilloscope

P \& O: Perturb and Observe

PS: Partial Shading

$D_{i}$ : $\quad$ Duty ratio of $i^{\text {th }}$ converter

$i_{\mathrm{PV} i}: \quad$ Instantaneous current of $i^{\text {th }}$ panel

$i_{0}: \quad$ Instantaneous output current

$v_{\mathrm{PV} i}: \quad$ Instantaneous voltage of $i^{\text {th }}$ panel

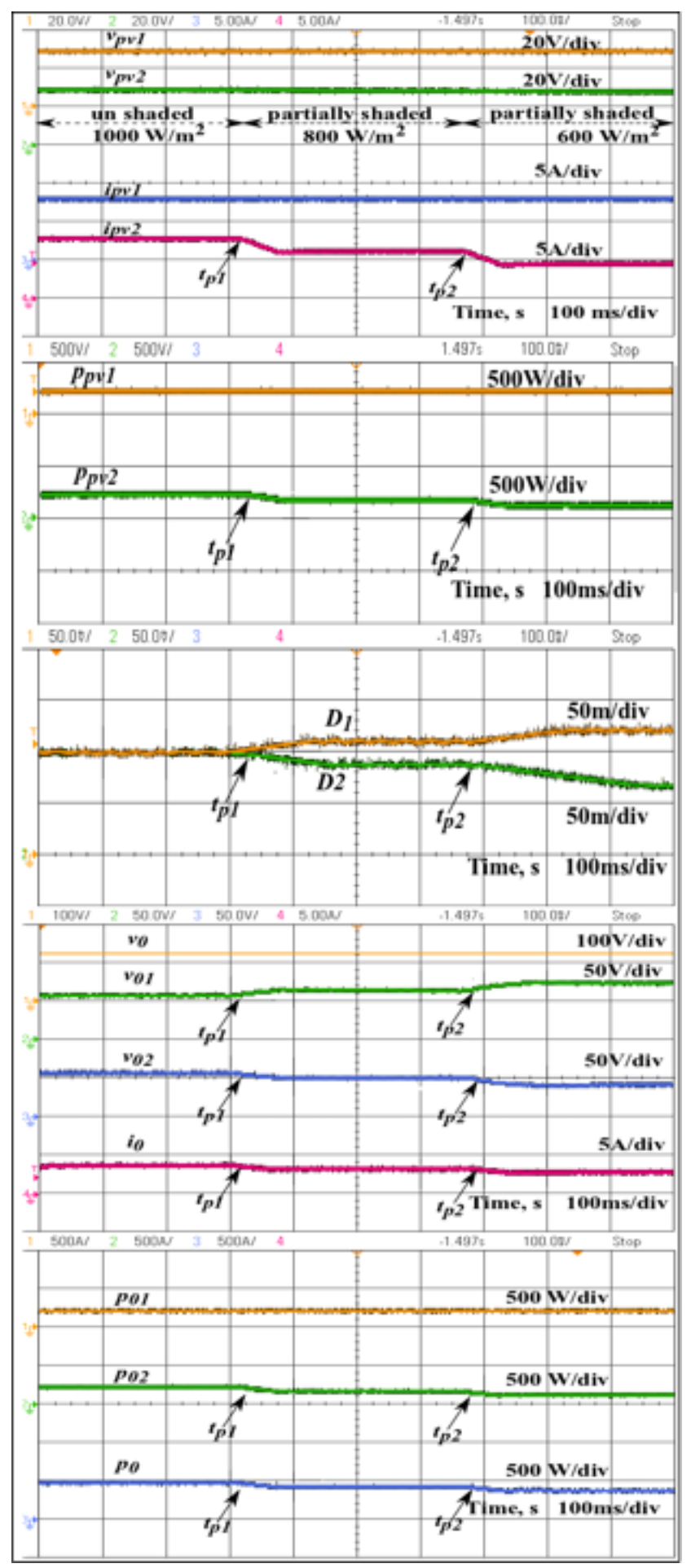

Fig. 13 Experimental results for series connected boost converters under PS condition

$v_{0 i}: \quad$ Instantaneous voltage of ith converter

$v_{0}: \quad$ DC microgrid voltage

$p_{\mathrm{PV} i}: \quad$ Instantaneous panels power

$p_{0}$ : Instantaneous output (DC microgrid) power

$p_{t l}: \quad$ Converter losses

$R_{s}, R_{s h}:$ Series and shunt resistance of PV panel where $i=1,2 \ldots \ldots \ldots \ldots \quad N,(N$ number of converters) 


\section{References}

[1] Ackermann, T., Andersson, G., Söder, L. "Distributed generation: a definition", Electric Power Systems Research, 57(3), pp. 195-204, 2001.

https://doi.org/10.1016/S0378-7796(01)00101-8

[2] Hatziargyriou, N., Asano, H., Iravani, R., Marnay, C. "Microgrids", IEEE Power and Energy Magazine, 5(4), pp. 78-94, 2007.

https://doi.org/10.1109/MPAE.2007.376583

[3] Peças Lopes, J. A., Hatziargyriou, N., Mutale, J., Djapic, P., Jenkins, N. "Integrating distributed generation into electric power systems: A review of drivers, challenges and opportunities", Electric Power Systems Research, 77(9), pp. 1189-1203, 2007. https://doi.org/10.1016/j.epsr.2006.08.016

[4] Pepermans, G., Driesen, J., Haeseldonckx, D., Belmans, R., D'haeseleer, W. "Distributed generation: definition, benefits and issues", Energy Policy, 33(6), pp. 787-798, 2005.

https://doi.org/10.1016/j.enpol.2003.10.004

[5] Femia, N., Petrone, G., Spagnuolo, G., Vitelli, M. "Optimization of perturb and observe maximum power point tracking method", IEEE Transactions on Power Electronics, 20(4), pp. 963-973, 2005. https://doi.org/10.1109/TPEL.2005.850975

[6] Alajmi, B. N., Ahmed, K. H., Finney, S. J., Williams, B. W. "Fuzzy-Logic-Control Approach of a Modified Hill-Climbing Method for Maximum Power Point in Microgrid Standalone Photovoltaic System", IEEE Transaction on Power Electronics, 26(4), pp. 1022-1030, 2011.

https://doi.org/10.1109/TPEL.2010.2090903

[7] Hsieh, G., Hsieh, G., Tsai, C., Wang, C. "Photovoltaic PowerIncrement-Aided Incremental-Conductance MPPT With TwoPhased Tracking", IEEE Transactions on Power Electronics, 28(6), pp. 2895-2911, 2013.

https://doi.org/10.1109/TPEL.2012.2227279

[8] Patel, H., Agarwal, V. "MATLAB-Based Modeling to Study the Effects of Partial Shading on PV Array Characteristics", IEEE Transactions on Energy Conversion, 23(1), pp. 302-310, 2008. https://doi.org/10.1109/TEC.2007.914308

[9] Koutroulis, E., Blaabjerg, F. "A New Technique for Tracking the Global Maximum Power Point of PV Arrays Operating Under Partial-Shading Conditions", IEEE Journal of Photovoltaics, 2(2), pp. 184-190, 2012. https://doi.org/10.1109/JPHOTOV.2012.2183578

[10] Saravanan, K., Sharmeela, C. "An intelligent reconfiguration technique for enhancing the power from photovoltaic module in partially shaded environments", International Journal of Power and Energy Conversion, 7(2), pp. 178-190, 2016. https://doi.org/10.1504/IJPEC.2016.076526

[11] Azab, M. "Global maximum power point tracking for partially shaded PV arrays using particle swarm optimisation", International Journal of Renewable Energy Technology, 1(2), pp. 211-235, 2019. https://doi.org/10.1504/IJRET.2009.027991

[12] Lian, K. L., Jhang, J. H., Tian, I. S. "A Maximum Power Point Tracking Method Based on Perturb-and-Observe Combined with Particle Swarm Optimization", IEEE Journal of Photovoltaics, 4(2), pp. 626-633, 2014.

https://doi.org/10.1109/JPHOTOV.2013.2297513
[13] Kermadi, M., Salam, Z., Ahmed, J., Berkouk, E. M. "An Effective Hybrid Maximum Power Point Tracker of Photovoltaic Arrays for Complex Partial Shading Conditions", IEEE Transactions on Industrial Electronics, 66(9), pp. 6990-7000, 2019.

https://doi.org/10.1109/TIE.2018.2877202

[14] Lin, B., Wang, L., Wu, Q. "Maximum Power Point Scanning for PV Systems Under Various Partial Shading Conditions", IEEE Transactions on Sustainable Energy, 2020. https://doi.org/10.1109/TSTE.2020.2965570

[15] Li, Q., Wolfs., P. "A Review of the Single Phase Photovoltaic Module Integrated Converter Topologies with Three Different DC Link Configurations", IEEE Transactions on Power Electronics, 23(3), pp. 1320-1333, 2008.

https://doi.org/10.1109/TPEL.2008.920883

[16] Kjaer, S. B., Pedersen, J. K., Blaabjerg, F. "A review of single-phase grid-connected inverters for photovoltaic modules", IEEE Transactions on Industry Applications, 41(5), pp. 1292-1306, 2005. https://doi.org/10.1109/TIA.2005.853371

[17] Alonso, R., Ibáñez, P., Martínez, V., Román, E., Sanz, A. "Analysis of performance of new distributed MPPT architectures", In: 2010 IEEE International Symposium on Industrial Electronics, Bari, Italy, 2010, pp. 3450-3455.

https://doi.org/10.1109/ISIE.2010.5637957

[18] Peter, P. K., Agarwal, V. "Current Equalization in Photovoltaic Strings With Module Integrated Ground-Isolated Switched Capacitor DC-DC Converters", IEEE Journal of Photovoltaics, 4(2), pp. 669-678, 2014. https://doi.org/10.1109/JPHOTOV.2014.2300754

[19] Giral, R., Carrejo, C. E., Vermeersh, M., Saavedra-Montes, A. J., Ramos-Paja, C. A. "PV field distributed maximum power point tracking by means of an active bypass converter", In: 2011 International Conference on Clean Electrical Power (ICCEP), Ischia, Italy, 2011, pp. 94-98. https://doi.org/10.1109/ICCEP.2011.6036360

[20] Adly, M., Strunz, K. "Irradiance-Adaptive PV Module Integrated Converter for High Efficiency and Power Quality in Standalone and DC Microgrid Applications", IEEE Transactions on Industrial Electronics, 65(1), pp. 436-446, 2018. https://doi.org/10.1109/TIE.2017.2723860

[21] Lavado Villa, L. F., Ho, T., Crebier, J.-C., Raison, B. "A Power Electronics Equalizer Application for Partially Shaded Photovoltaic Modules", In: IEEE Transactions on Industrial Electronics, 60(3), pp. 1179-1190, 2013.

https://doi.org/10.1109/TIE.2012.2201431

[22] Ramli, M. Z., Salam, Z. "A Simple Energy Recovery Scheme to Harvest the Energy from Shaded Photovoltaic Modules During Partial Shading", IEEE Transactions on Power Electronics, 29(12), pp. 6458-6471, 2014. https://doi.org/10.1109/TPEL.2014.2302007

[23] Sharma, P., Agarwal, V. "Exact Maximum Power Point Tracking of Grid-Connected Partially Shaded PV Source Using Current Compensation Concept", IEEE Transactions on Power Electronics, 29(9), pp. 4684-4692, 2014. https://doi.org/10.1109/TPEL.2013.2285075 
[24] Petrone, G., Ramos-Paja, C. A., Spagnuolo, G., Vitelli, M. "Granular control of photovoltaic arrays by means of a multi-output Maximum Power Point Tracking algorithm", Progress in Photovoltaics: Research and Applications, 21(5), pp. 918-932, 2013. https://doi.org/10.1002/pip.2179

[25] Delavaripour, H., Dehkordi, B. M., Zarchi, H. A., Adib, E. "Increasing Energy Capture from Partially Shaded PV String Using Differential Power Processing", IEEE Transactions on Industrial Electronics, 66(10), pp. 7672-7682, 2019. https://doi.org/10.1109/TIE.2018.2883271

[26] Zhou, G., Tian, Q., Leng, M., Fan, X., Bi, Q. "Energy management and control strategy for DC microgrid based on DMPPT technique", IET Power Electronics, 13(4), pp. 658-668, 2020. https://doi.org/10.1049/iet-pel.2019.0383

[27] Maammeur, H., Hamidat, A., Loukarfi, L. "A numerical resolution of the current-voltage equation for a real photovoltaic cell", Energy Procedia, 36, pp. 1212-1221, 2013. https://doi.org/10.1016/j.egypro.2013.07.137

[28] Walker, G. "Evaluating MPPT Converter Topologies Using a MATLAB PV Model", Journal of Electrical \& Electronics Engineering, Australia, 21(1), pp. 49-55, 2001.

\section{Appendix A}

The IGBT and diode power loss calculation is attained by the equations given in $[31,32]$.

The total power loss in IGBT is the sum of the conduction and switching losses, where, the conduction loss of IGBT

$P_{\text {scond }}=v_{c(\mathrm{on})}\left(\frac{i_{o}}{1-D}\right)+R_{s(\mathrm{on})} D\left(\frac{i_{o}}{1-D}\right)^{2}$.

Switching loss of IGBT is

$P_{s s w}=\left(E_{0 n}+E_{\text {off }}\right) f_{s w}$.

In this experimentation, the boost converter is fabricated with an IGBT (IRGTI090U06) and diode (IXYS DSEI30-06A). The parameters of both the devices are $v_{c(\mathrm{on})}=2.0 \mathrm{~V}$ for $30 \mathrm{~A}, R_{s(\mathrm{on})}=33.33 \mathrm{~mW}, t_{f}=250 \mathrm{~ns}$, $E_{0 n}=E_{\text {off }}=0.05 \mathrm{~mJ} / \mathrm{A}$, and $f_{s w}=10 \mathrm{kHz}$ for IGBT and $v_{D(\mathrm{on})}=1.01 \mathrm{~V}, R_{D(\mathrm{on})}=7.1 \mathrm{~mW}, v_{f r}=7 \mathrm{~V}$, and $t_{f r}=350 \mathrm{~ns}$ for diode.

The conduction loss of diode is

$$
P_{D c o n}=v_{D(\text { on })} i_{0}+R_{D(\text { on })} i_{0}^{2} \text {. }
$$

[29] Meyer, E. L., van Dyk, E. E. "Assessing the reliability and degradation of photovoltaic module performance parameters", IEEE Transactions on Reliability, 53(1), pp. 83-92, 2004. https://doi.org/10.1109/TR.2004.824831

[30] King, D. L., Quintana, M. A., Kratochvil, J. A., Ellibee, D. E., Hansen, B. R. "Photovoltaic module performance and durability following long-term field exposure", Progress in Photovoltaics: Research and Applications, 8(2), pp. 241-256, 2000. https://doi.org/10.1002/(SICI)1099-159X(200003/04)8:2 $<241:$ :AID-PIP290>3.0.CO;2-D

[31] Graovac, D., Pürschel, M., Kiep, A. "MOSFET Power Losses Calculation Using the Data-Sheet Parameters", Infineon Technologies AG, Neubiberg, Germany, Application Note, V 1.1, 2006.

[32] Bürkel, R., Schneider, T. "Fast Recovery Epitaxial Diodes (FRED): Characteristics - Applications - Examples", IXYS, IXAN0044, 1999.

The switching loss of the diode is

$P_{D s w}=\left(E_{D 0 n}+E_{D \text { off }}\right) f_{s w}$.

The off-state energy losses are normally neglected [32]. The on-state energy loss is

$E_{D \text { on }}=\frac{1}{2} i_{0} v_{f r} t_{f r}$

where $t_{f r}$ and $v_{f r}$ are the turn-on recovery time and overvoltage and the procedure for calculating these values are given in [32]. The power loss due to the inductive resistance of the filter is

$P_{\text {ind }}=R_{\text {ind }}\left(\frac{i_{o}}{1-D}\right)^{2}$.

Hence, the total converter loss is

$P_{t l}=P_{s c o n d}+P_{s w}+P_{D(\text { on })}+P_{D s w}$. 